\title{
Patient-Reported Outcomes in First-Line Antiretroviral Therapy: Results From NEAT001/ANRS143 Trial Comparing Darunavir/Ritonavir in Combination With Tenofovir/Emtricitabine or Raltegravir
}

\author{
Elizabeth C. George, PhD, * Raffaella Bucciardini, PhD, $\dagger$ Laura Richert, MD PhD, $\neq$ Nikos Dedes, $\S$ \\ Vincenzo Fragola, MD, † Pythia Nieuwkerk, PhD,\| Bruno Spire, MD, $\mid$ Alain Volny-Anne, BA, $\S$ \\ Brian West, § Jean-Michel Molina, MD,\#** Andrzej Horban, MD, PhD, †† Julie Fox, MD, $\neq$ \\ Anton Pozniak, PhD, $\S \S$ Stefano Vella, MD, † Monique Termote, MSc, $\neq$ and François Raffi, MD, PhD, \|\| \\ the NEAT 001/ANRS 143 Study Group
}

\begin{abstract}
Background: There are few data comparing patient-reported outcomes (PROs) in randomized trials of initial antiretroviral therapy. We present results from a substudy of the NEAT001/ ANRS143 trial.
\end{abstract}

Methods: The randomized trial compared first-line DRV/r 800/100 mg once daily plus RAL $400 \mathrm{mg}$ twice daily and DRV/r plus TDF/ FTC 245/200 mg once daily. Changes in PROs were assessed with 3 questionnaires: EuroQoL 5 domains (EQ-5D), Center for Epidemiologic Studies Depression (CES-D) scale, and HIV Treatment Satisfaction Questionnaire. Major depressive disorder (MDD) was defined as CES-D $\geq 16$. General estimating equations were used to model change over 96 weeks in PROs from baseline.
Results: Of the 805 participants, 797 (99\%) contributed to the substudy. Baseline PRO data were similar for the 2 randomized groups. Health status improved over time with a mean increase in EQ-5D visual analogue scale (VAS) of 8.0 by W96 [95\% confidence interval (CI): 6.5 to $9.4 ; P<0.001$ ], and no statistically significant differences between groups (difference of 0.3 on VAS score $(95 \%$ CI: -1.7 to 2.3 ); $P=0.7$, global $P$ value $\geq 0.05$ for all domains over follow-up). There was no significant difference between groups on CES-D [difference of -0.1 (95\% CI: -1.3 to 1.1$) ; P=0.9$ ], or MDD during follow-up, adjusted for baseline MDD (odds ratio $=0.98$, 95\% CI: 0.82 to $1.18 ; P=0.9)$. RAL $+\mathrm{DRV} / \mathrm{r}$ group had lower level of convenience $(P=0.03)$ and fitted less well into patients' lifestyle $(P=0.007)$ than the TDF/FTC $+\mathrm{DRV} / \mathrm{r}$ regimen, and was associated

Received for publication March 12, 2018; accepted July 23, 2018.

From the *MRC CTU at UCL, Institute of Clinical Trials and Methodology, UCL, London, United Kingdom; †National Center for Global Health, Istituto Superiore di Sanità (The National Institute of Health), Rome, Italy; INSERM, Bordeaux Population Health Research Center, University of Bordeaux, Bordeaux, France; $\S$ European AIDS Treatment Group, Brussels, Belgium; \#Department of Medical Psychology, Academic Medical Center, Amsterdam School of Public Health, Amsterdam, the Netherlands; IINSERM, IRD, SESSTIM, Sciences Economiques \& Sociales de la Santé \& Traitement de l'Information Médicale, Fac médecine Timone, Aix Marseille Univ, Marseille Cedex, France; \#Department of Infectious Diseases, Saint-Louis hospital, Paris, France; **Assistance Publique Hopitaux de Paris, University of Paris Diderot, Paris, France; ††Warsaw Medical University and Hospital for Infectious Diseases, Warsaw, Poland; $+\$$ Guys and St Thomas' NHS trust, London, United Kingdom; §§Chelsea and Westminster Hospital NHS Foundation Trust, London, United Kingdom; and \|\| Infectious Diseases Department and INSERM CIC 1413, University hospital of Nantes, Nantes, France.

NEAT is a project funded to the Instituto Superiore di Sanità-Rome, by the European Union under the Sixth Framework Programme, project number LSHP-CT2006-037570. The trial was also supported by Gilead Sciences, Janssen Pharmaceuticals, and Merck Laboratories. The French National Institute for Health and Medical Research-France Recherche Nord \& Sud Sida-HIV Hepatites (Inserm-ANRS) was the sponsor and a funder of the trial. E.C.G. was also supported by the UK Medical Research Council (Grant number MC_U122886352).

Presented in part as a poster at IAS 2017; July 24, 2017; Paris, France.

F.R. has received research funding or honoraria from, or consulted for, Abbvie, Bristol-Myers Squibb, Gilead Sciences, Janssen, MSD, and ViiV Healthcare. B.S. has received honorarium fees from Gilead, MSD, and Jansen-Cilag. A.P. has received research funding and honoraria from Merck, Janssen, Gilead, and Viiv. J.-M.M. has sat on advisory boards for Gilead, Merck, Janssen, Viiv BMS, and Teva and received research funding from Gilead. N.D. has received financial support and been a board member of Gilead, Merck, and Janssen. The remaining authors have no conflicts of interest to disclose.

R.B., L.R., N.D., V.F., P.N., B.S., A.V.-A., B.W., S.V., and F.R. designed the study as a substudy of the NEAT001/ANRS143 trial. J.-M.M., A.H., J.F., A.P., and F.R. enrolled participants into the study. M.T. coordinated data collection and entry. All authors participated in data interpretation. Statistical analyses were performed by E.C.G. The manuscript was drafted by E.C.G., R.B., and F.R. All authors provided input to the report and approved the final version of the manuscript.

Supplemental digital content is available for this article. Direct URL citations appear in the printed text and are provided in the HTML and PDF versions of this article on the journal's Web site (www.jaids.com).

Members of the NEAT 001/ANRS 143 Study Group are listed in the Appendix 1.

Correspondence to: Elizabeth C. George, PhD, MRC CTU at UCL, Institute of Clinical Trials and Methodology, UCL, 90 High Holborn, London, WC1V 6LJ, United Kingdom (e-mail: elizabeth.george@ucl.ac.uk).

Copyright (C) 2018 The Author(s). Published by Wolters Kluwer Health, Inc. This is an open-access article distributed under the terms of the Creative Commons Attribution-Non Commercial License 4.0 (CCBY-NC), where it is permissible to download, share, remix, transform, and buildup the work provided it is properly cited. The work cannot be used commercially without permission from the journal. 
with lower treatment satisfaction [median score: $53 \mathrm{RAL}+\mathrm{DRV} / \mathrm{r}$ vs $55 \mathrm{TDF} / \mathrm{FTC}+\mathrm{DRV} / \mathrm{r}(P=0.001)]$.

Conclusion: PROs improved after starting antiretroviral therapy, with no statistically significant difference between groups. The lower satisfaction with RAL + DRV/r may be explained by twicedaily administration.

Key Words: quality of life, raltegravir, treatment satisfaction, EQ$5 \mathrm{D}$, ritonavir-boosted darunavir, health improvement

(J Acquir Immune Defic Syndr 2018;79:519-526)

\section{INTRODUCTION}

Antiretroviral therapy (ART) has dramatically reduced mortality and morbidity at all stages of HIV infection, ${ }^{1,2}$ making an overall improvement of patients' health status an important goal of therapy. In fact, according to most recent guidelines, one of the key treatment goals is to "prolong the quality of survival." 3 In this context, patient-reported outcomes (PROs) have been recognized as an important measure of health that deserves to be taken into account, together with the traditional efficacy and safety parameters, when measuring a patient's health status both in research and clinical practice. Indeed, there is compelling evidence that both HIV infection and prolonged ART can impair PROs such as health-related quality of life (HRQL), fatigue, and work productivity. ${ }^{4}$ Assessment of PRO measures is of particular interest when two or more therapeutic strategies have the same clinical efficacy because PROs are the major drivers of adherence to long-term ART. ${ }^{5}$ In fact, PROs during treatment may explain the gap that is frequently reported between efficacy rates and those reported for the effectiveness of ART in the real world practices. PROs are also important surrogates for patients' experience with their disease and its treatment. ${ }^{6}$ Combined, these reasons make PROs important endpoints for clinical trials to identify the strategy that maximize the patient's health status and irreplaceable sources of important information in clinical practice. $^{7}$ A large European NEAT001/ANRS143 randomized multicenter trial that compared 2 different ART regimens for first-line treatment in naive patients showed non-inferiority based on a virological composite primary outcome at 96 weeks. There was also no difference in the frequency of serious or treatment-modifying adverse events. We report the results of a specific PROs' substudy nested within the NEAT001/ANRS143 large clinical trial.

\section{PARTICIPANTS AND METHODS}

\section{Study Treatment and Participants}

NEAT001/ANRS143 was a randomized, open-label, non-inferiority trial conducted in 15 European countries between August 2010 and October 2013. The full study design and results have been previously reported. ${ }^{8}$ Briefly, 805 naive HIV-infected adults were randomly assigned in a 1:1 ratio to receive oral treatment with $800-\mathrm{mg}$ darunavir and 100-mg ritonavir once daily plus either 400-mg raltegravir twice daily [nucleotide reverse transcriptase inhibitor (NtRTI)-sparing regimen) or tenofovir/emtricitabine in a 245- and 200-mg fixed dose combination once daily (standard regimen). Participants were offered to participate in the PROs' substudy. Ethics committee approval was obtained for all participating centers, in accordance with the principles of the Declaration of Helsinki. All trial participants gave written informed consent. The study was registered with ClinicalTrials. gov (NCT01066962).

\section{Data Collection}

Participants attended study centers at screening, baseline (randomization), weeks $2,4,8,12,18,24,32$, $48,64,80$, and 96, and every $12-16$ weeks thereafter. Each visit included assessment of vital signs and adverse events, physical examination, and collection of blood samples for full blood cell counts and serum chemistry, liver function, and immunovirological measurements, except at W2 for the latter. Adverse events recorded during the study were grouped based on the body system as previously described. $^{8}$

\section{Patient-Reported Outcomes}

PROs were collected at baseline and during scheduled follow-up visits at weeks $4,12,24,48$, and 96 through selfadministered questionnaires in participants' native languages. Four PRO questionnaires were used in this study: (1) the EuroQoL 5 domains (EQ-5D), ${ }^{9}$ a widely used generic questionnaire for measuring health-related quality of life (HRQL), that includes 2 parts. The EQ-5D self-classifier asks participants to describe their health on 5 domains: (mobility, self-care, usual activities, pain/discomfort, and anxiety/depression) and 3 levels: (1) indicating "no problem," (2) indicating "some or moderate problems," and (3) indicating "extreme problems/impossible to do." The EQVAS is a visual analogue scale (VAS) that takes values between 100 (best imaginable health) and 0 (worst imaginable health) on which participants provide an overall measure of their health status; (2) the ISS-NEAT HIV symptoms scale, a self-administered list of 38 symptoms, ${ }^{10}$ that evaluates the impact of symptoms over the past 4 weeks through a Likert 5point intensity scale rated from "not at all" $=1$ to "a very great deal" = 5; (3) the Center for Epidemiologic Studies Depression (CES-D), that asks participants to rate how often over the past week they experienced symptoms associated with depression, with response options ranging from 0 to 3 for each item $(0=$ rarely or none of the time, $1=$ some or little of the time, 2 = occasionally or moderately, and $3=$ most or all the time). Major depressive disorder (MDD) was defined as CES-D $\geq 16$. In this study, a short version of 10 items was used $^{11}$; and (4) the HIV Treatment Satisfaction Questionnaire (HIVTSQ) measuring overall satisfaction with HIV treatment and by specific domains such as convenience, ease of use, and flexibility through a 10 -item self-reported scale with a maximum possible score of $60 .^{12}$ 

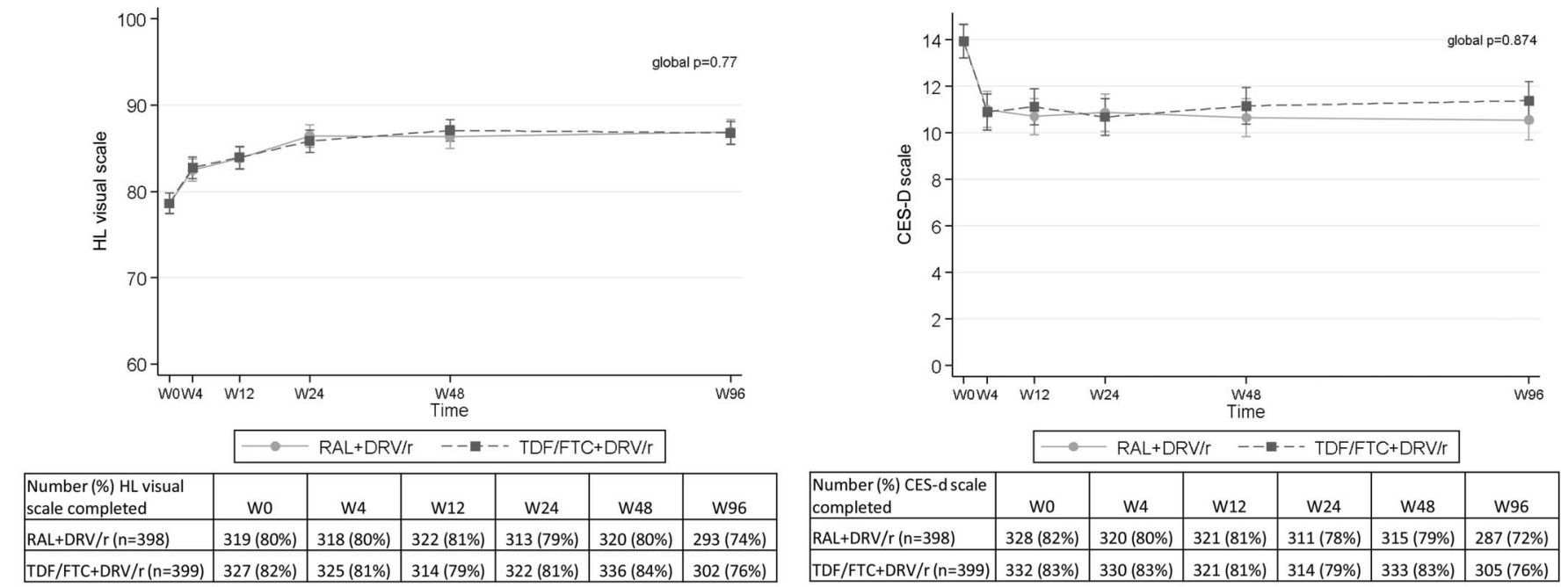

A B

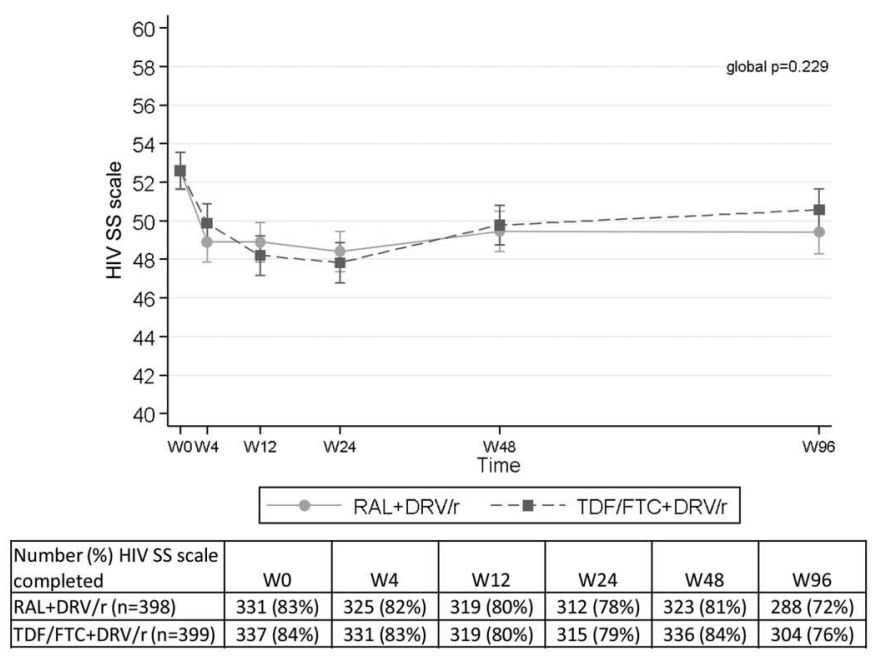

C

NB: Global p-value for difference between trial arms over time from randomization.

FIGURE 1. A, EQ-VAS for current health over follow up; (B) CES-d scale over follow up; (C) HIV symptoms scale over follow up.

\section{Statistical Analyses}

Together with clinicodemographic parameters, the PROs at and during follow-up were compared between the 2 trial treatments using Pearson's $\chi^{2}$ test for categorical variables or $t$ tests and Wilcoxon rank sum tests for continuous variables. The two treatment groups were compared as randomized, according to the intention-to-treat principle. Generalized estimating equations (GEEs) including all participants that contributed one or more questionnaires were used to model: change over time in PROs from baseline; odds of MDD during the trial adjusted for baseline MDD; and odds of having moderate or severe problems (compared with no problems) on EQ-5D domains adjusted for baseline levels. GEEs were used because the models can handle missing measurements without the need for imputation and have been shown to be a viable analysis for PROs in HIV trial data. ${ }^{13}$ Within the GEE models, potential differences between arms and visit weeks were accounted for with interaction terms.
Sensitivity analyses were performed by imputing missing values of PROs at each time point using multiple imputation with chained equations (with predictive mean matching for CES-D and EQ-VAS, and regression for HIV symptoms scale) and then changing the imputed values to test the assumption that the group who had missing data had systematically worse or better outcomes. ${ }^{14}$ Baseline factors that were associated with change in EQ-5D VAS over time (age, sex, country of enrollment, body mass index, mode of infection, ethnicity, HIV stage, CD4, and $\log _{10}$ plasma HIV RNA) were included in the GEE model. Levels of treatment satisfaction between groups were compared with $\chi^{2}$ tests in participants with questionnaires at baseline and W96 and logistic regression for the \% very satisfied at W96 adjusted for baseline factors. This time point was in line with the primary endpoint for the main trial measured once all participants had reached W96. For this PROs' substudy, no predetermined 
sample size was calculated. Statistical analyses were performed using Stata v14.0.

\section{RESULTS}

\section{Baseline Characteristics and Data Completeness}

Of the 805 participants, 797 (99\%) contributed to the substudy: $683 / 797(86 \%)$ at baseline, $611(77 \%)$ at W96, and $526(66 \%)$ at both visits. A minimum of $74 \%$ participants contributed to PRO data at each visit and $>80 \%$ contributed at visits within the first 12 weeks (Fig. 1A). There was no significant difference between randomized groups for completeness of data at each visit and overall (global $P$ value from GEE models for missingness of CES-D scale, EQ-VAS, and HIV symptoms scale was $0.10,0.41$, and 0.28 , respectively). Baseline characteristics and PROs of the participants contributing at baseline were not different between treatment groups (Table 1) and were similar to those of the 805 participants randomized to the main NEAT001/ANRS143 trial.

\section{PRO Measures}

There were no significant differences between randomized groups for any of the EQ-5D domains including VAS over time (Table 2 and Fig. 1A). During follow-up, an improvement of participant overall health status (EQ-VAS) was observed in both randomized groups, with a marked increase during the first 24 weeks of therapy \{difference from baseline of 7.5 [95\% confidence interval (CI): 6.5 to 8.5]; $P<$ $0.001\}$, then a plateau; however, there were no statistically significant differences between randomized groups at any time point (Fig. 1A). A reduction of the HIV symptoms scale was observed in first 4 weeks [difference from baseline of -3 (95\% CI: -4 to -2$) ; P<0.001]$ for standard regimen, with stabilization up to W96 and no statistically significant differences between the 2 randomized groups (Fig. 1B). Depression/anxiety as measured on the CES-D scale also improved, as by week 4, statistically significant improvement was evidenced in both groups [difference of -3 ( $95 \%$ CI: -4 to $-2) ; P<0.001$ ], with no difference between the 2 groups (Fig. 1C). Sensitivity analyses showed that under the assumptions that participants with missing PROs either had systematically worse or better outcomes, there were no significant differences between randomized groups for EQVAS, CES-D, or HIV symptoms scale (Table 1, Supplemental Digital Content http://links.lww.com/QAI/B211). There was no evidence of a difference between groups in MDD during the 96-week duration of the study [odds ratio (OR) $0.98,95 \%$ CI: 0.82 to 1.18$]$. At W96, participants in the NtRTI-sparing regimen reported significantly lower median score in treatment satisfaction than participants in the standard regimen $\{53$ [interquartile range (IQR) 48-58] vs 55 (IQR 5059); Kruskal-Wallis $P=0.001\}$. There were no differences between groups on satisfaction regarding general satisfaction, satisfaction with control and understanding of disease, side effects, or wish to continue current treatment (Table 3).

\section{PRO Predictors}

Age (Wald test $P<0.001$ ) and country of enrollment (overall Wald test $P=0.05$ ) were found to be independently associated with change in overall health status adjusting for the other baseline factors and baseline EQ-5D VAS. Older age was associated with lower VAS [decrease of $-0.1(95 \%$ CI: -0.2 to -0.05$)$ per age year], and 2 countries were associated with increased VAS \{Hungary $[\mathrm{n}=6$, increase of

TABLE 1. Baseline Patient-Reported Outcomes and Characteristics

\begin{tabular}{|c|c|c|}
\hline Patient-Reported Outcomes & $\mathbf{R A L}+\mathbf{D R V} / \mathbf{r}$ & TDF/FTC + DRV/r \\
\hline $\begin{array}{l}\text { Median (IQR) CES-D } \\
\text { score; N }\end{array}$ & $12(7,18) ; 328$ & $12(7,19) ; 332$ \\
\hline Major depressive disorder (\%) & $121 / 328(37 \%)$ & $110 / 332(33 \%)$ \\
\hline $\begin{array}{l}\text { Median (IQR) HIV symptoms } \\
\text { scale; N }\end{array}$ & $49(43,59) ; 331$ & $49(42,59) ; 337$ \\
\hline \multicolumn{3}{|l|}{$\begin{array}{l}\text { EuroQol (EQ-5D) domains } \\
(\% \text { moderate or severe } \\
\text { problems })\end{array}$} \\
\hline Mobility & $11 / 335(3 \%)$ & $11 / 342(3 \%)$ \\
\hline Self-care & $2 / 335(<1 \%)$ & $5 / 341(1 \%)$ \\
\hline Usual activities & $26 / 336(8 \%)$ & $26 / 340(8 \%)$ \\
\hline Pain/discomfort & $79 / 335(24 \%)$ & $90 / 341(26 \%)$ \\
\hline Anxiety/depression & $143 / 336(43 \%)$ & $145 / 340(43 \%)$ \\
\hline $\begin{array}{l}\text { Median (IQR) EQ-5D } \\
\text { VAS; N }\end{array}$ & $80(70-90) ; 319$ & $80(70-90) ; 327$ \\
\hline $\begin{array}{l}\text { Baseline characteristics for } \\
\text { those with any baseline } \\
\text { PRO recorded }\end{array}$ & $\mathrm{N}=340$ & $\mathrm{~N}=343$ \\
\hline Mean (SD) age (yr) & $38(10)$ & $39(10)$ \\
\hline Male $(\%)$ & $299(88 \%)$ & $305(89 \%)$ \\
\hline $\begin{array}{l}\text { Mean (SD) baseline CD4 } \\
\left(\mathrm{mm}^{3}\right)\end{array}$ & $328(7)$ & $315(7)$ \\
\hline $\begin{array}{l}\text { Mean (SD) baseline HIV } \\
\text { RNA }\left(\log _{10} \mathrm{c} / \mathrm{mL}\right)\end{array}$ & $10.9(0.08)$ & $10.8(0.08)$ \\
\hline $\begin{array}{l}\text { Mean (SD) body mass index } \\
\left(\mathrm{kg} / \mathrm{m}^{2}\right)\end{array}$ & $23.8(0.2)$ & $23.7(0.2)$ \\
\hline \multicolumn{3}{|l|}{ Mode of contamination* } \\
\hline Homosexual/bisexual sex & $230(72 \%)$ & $235(71 \%)$ \\
\hline Heterosexual sex & $81(25 \%)$ & $83(25 \%)$ \\
\hline Intravenous blood use & $7(2 \%)$ & $10(3 \%)$ \\
\hline $\begin{array}{l}\text { Blood or blood product } \\
\text { receipt }\end{array}$ & $1(<1 \%)$ & $0(0 \%)$ \\
\hline Other & $3(1 \%)$ & $4(1 \%)$ \\
\hline \multicolumn{3}{|l|}{ Ethnic origin } \\
\hline White & $281(83 \%)$ & $284(83 \%)$ \\
\hline Black & $43(13 \%)$ & $36(11 \%)$ \\
\hline Asian & $6(2 \%)$ & $8(2 \%)$ \\
\hline Other & $10(3 \%)$ & $15(4 \%)$ \\
\hline \multicolumn{3}{|l|}{ HIV stage } \\
\hline A & $279(82 \%)$ & $284(83 \%)$ \\
\hline $\mathrm{B}$ & $44(13 \%)$ & $43(13 \%)$ \\
\hline $\mathrm{C}$ & $17(5 \%)$ & $18(5 \%)$ \\
\hline
\end{tabular}

*Percentages are based only on patients with available data $(\mathrm{RAL}+\mathrm{DRV} / \mathrm{r} \mathrm{n}=318$, $\mathrm{TDF}-\mathrm{FTC}+\mathrm{DRV} / \mathrm{r} \mathrm{n}=329) ; 7$ patients had more than one risk factor $(\mathrm{RAL}+\mathrm{DRV} / \mathrm{r} \mathrm{n}=$ 4, TDF-FTC+DRV/r n = 3). There was no evidence of differences in any baseline characteristic or PRO between the randomized arms in those that had any baseline PRO recorded. 
TABLE 2. Odds Ratios of RAL + DRV/r vs TDF/FTC + DRV/r for Having Moderate or Severe Problems in the EQ-5D Domains Over Follow-up

\begin{tabular}{|c|c|c|c|c|c|c|}
\hline \multirow[b]{2}{*}{ EQ-5D Domain } & \multicolumn{6}{|c|}{ OR of RAL + DRV/r vs TDF/FTC + DRV/r (95\% CI) } \\
\hline & W4 & W12 & W24 & W48 & W96 & Global, $P$ \\
\hline Mobility $(\mathrm{n}=677)$ & $0.77(0.32$ to 1.90$)$ & $0.52(0.20$ to 1.36$)$ & $4.18(1.12$ to 15.66$)$ & $2.19(0.83$ to 5.82$)$ & $2.41(0.97$ to 5.96$)$ & 0.05 \\
\hline Self-care $(n=677)$ & $1.26(0.15$ to 10.93$)$ & $0.49(0.13$ to 1.92$)$ & $0.71(0.05$ to 9.51$)$ & $0.26(0.03$ to 2.63$)$ & $0.24(0.02$ to 2.35$)$ & 0.80 \\
\hline Usual activity $(\mathrm{n}=676)$ & $0.99(0.47$ to 2.07$)$ & $0.98(0.45$ to 2.11$)$ & $0.98(0.43$ to 2.24$)$ & $0.77(0.35$ to 1.66$)$ & $0.75(0.33$ to 1.68$)$ & 0.99 \\
\hline $\begin{array}{l}\text { Pain or discomfort } \\
\qquad(\mathrm{n}=676)\end{array}$ & $0.74(0.48$ to 1.16$)$ & $1.13(0.72$ to 1.79$)$ & $1.63(1.01$ to 2.64$)$ & $0.96(0.60$ to 1.52$)$ & $1.12(0.69$ to 1.82$)$ & 0.26 \\
\hline $\begin{array}{l}\text { Anxiety or depression } \\
\qquad(\mathrm{n}=676)\end{array}$ & $1.09(0.72$ to 1.67$)$ & $1.14(0.74$ to 1.74$)$ & $0.87(0.57$ to 1.34$)$ & $1.10(0.71$ to 1.69$)$ & $1.33(0.84$ to 2.10$)$ & 0.85 \\
\hline
\end{tabular}

$11(95 \%$ CI: 1 to 21$) ; P=0.03]$ and Portugal $[\mathrm{n}=21$, increase of $12(95 \%$ CI: 3 to 21$) ; P=0.007]\}$. The potential baseline predictors were also included in the models for change in CES-D and HIV symptoms scale adjusted for their baseline values. Age was found to be an independent predictor of change in the model for HIV symptoms scale with older age associated with an increased score [increase of 0.1 per age year (95\% CI: 0.03 to 0.2$) ; P=0.006]$. Sex was found to be an independent predictor of change in CES-D score with female sex (including transgender male to female) associated with an increased CES-D score [increase of 2 (95\% CI: 0.1 to 4); $P=0.04]$.

\section{Multivariate Analysis of Treatment Satisfaction}

A logistic regression model was fitted for the proportion of participants who responded with 5 or 6 (very satisfied) on each question on the HIVTSQ at W96 adjusted for treatment group, age at enrollment, sex, and change from baseline in the other PRO measures (CES-D, EQ-5D VAS, and HIV symptoms scale). The proportions of participants feeling very satisfied with convenience, extent with which treatment fits into their lifestyle, and who would recommend their treatment to a friend were higher in the standard regimen after adjustment (Table 3 ).

\section{DISCUSSION}

Our data indicate that most PRO domain scores measured with 4 different validated instruments significantly improved during first-line antiretroviral treatment. Previous studies have shown reduction of fatigue and HIV symptoms in HIV-infected patients initiating ART, ${ }^{15,16}$ but few studies have evaluated PROs in a randomized comparative study.

In our study, improvement of PRO scores started shortly after the initiation of therapy and then plateaued between 6 months and 2 years on continuous therapy, suggesting that PROs' benefit was maximal when plasma virologic suppression was achieved and did not increase thereafter. For 3 of the PRO measures assessed, HRQL, HIV symptoms scale, and CES-D, improvement was not different between the 2 randomized groups either overall or any time point of follow-up. These results represent additive arguments to the hypothesis that PRO improvement is related to virologic suppression achievement rather than to a specific drug regimen. However, it is interesting to note that PRO improvement in the 1 st week after treatment initiation was of similar magnitude in both randomized groups, although at W4 and W24, a significantly higher proportion of participants achieved virologic suppression on the NtRTI regimen, while at 96 weeks, both regimens were virologically noninferior. ${ }^{8}$ The underlying mechanisms to connect HIV plasma suppression with PRO improvement are yet to be elucidated. ${ }^{17}$ Some putative mechanisms may be related to the improvement of cytokine and other metabolites profile, both in peripheral blood and central nervous system, because of the viral suppression that could in turn positively impact patients' experience. ${ }^{18}$ Viral suppression might thus improve fatigue and other PROs related to chronic HIV infection. ${ }^{19}$

Our multivariate analysis showed an association between older age and lower health-related outcomes. Poorer PROs in older patients has been reported in many studies on $\mathrm{HCV}$ treatment, including the most recent ones with highly effective and very well-tolerated direct-acting antiviral regimens. ${ }^{20}$ Older age was negatively associated with physical Fatigue Impact Scale subscores in an observational study on raltegravir, ${ }^{19}$ while in a review of literature, there was no association between age and fatigue in most studies. ${ }^{21} \mathrm{HIV}$ disease factors, such as US Centers for Disease Control and Prevention (CDC) stage, CD4, and plasma HIV RNA, did not influence PRO improvement, indicating that benefit of HIV therapy on quality of life was seen whatever the baseline immunovirological status of the patient, taking into account that 15 patients in our study had CD4 cell counts $<200 / \mathrm{mm}^{3}$ and only $5 \%$ CDC stage C HIV infection.

Association of worsening of depression score in women over time might be related to higher difficulty to cope with HIV disease or to higher vulnerability or perceived stigma. Most studies in an HIV-positive population have showed a higher rate of depression in women than men; ${ }^{22}$ however, no longitudinal study over a 2-year period has been reported. The difference found in improved overall health status by country, as measured by EQ-VAS, was driven by differences in Hungary and Portugal, and could be due to the small numbers enrolled in the trial in these countries because modest absolute differences from baseline in small groups can have a large impact. HIVTSQ scores for treatment convenience, fitting into lifestyle, and willingness to recommend to 
TABLE 3. Odds Ratios of RAL + DRV/r vs TDF/FTC + DRV/r for Proportion With a "Very Satisfied" Response on the HIVTSQ at W96 and Impact of Adjusting for Potential Confounders by Logistic Regression

\begin{tabular}{|c|c|c|c|c|c|}
\hline $\begin{array}{l}\text { Treatment Satisfaction } \\
\text { Question at W96 [\% Very } \\
\text { Satisfied (5 or 6)] }\end{array}$ & $\mathbf{R A L}+\mathbf{D R V} / \mathbf{r}$ & $\begin{array}{c}\text { TDF/FTC + } \\
\text { DRV/r }\end{array}$ & $\begin{array}{c}\text { Unadjusted OR } \\
\text { (95\% CI) for RAL vs } \\
\text { TDF/FTC }\end{array}$ & Adjusted OR* & $\begin{array}{c}\text { Other Significant Factors in Model } \\
\text { [OR (95\% CI)] }\end{array}$ \\
\hline $\begin{array}{l}\text { Satisfied with current } \\
\text { treatment }\end{array}$ & $238 / 268(89 \%)$ & $269 / 288(93 \%)$ & $\begin{array}{c}1.78(0.98 \text { to } 3.25) \\
P=0.06\end{array}$ & $\begin{array}{c}1.55(0.75 \text { to } 3.19) \\
P=0.24\end{array}$ & Age [1.03 (95\% CI: 1.0 to 1.08$)]$ \\
\hline $\begin{array}{l}\text { Satisfaction with how well } \\
\text { HIV was controlled }\end{array}$ & $250 / 268(93 \%)$ & $277 / 287(97 \%)$ & $\begin{array}{c}1.99(0.90 \text { to } 4.40) \\
P=0.09\end{array}$ & $\begin{array}{c}1.99(0.77 \text { to } 5.18) \\
P=0.16\end{array}$ & $\begin{array}{l}\text { HIV symptoms scale change from } \\
\text { baseline }[0.92 \text { ( } 95 \% \text { CI } 0.89 \text { to } \\
0.96)] \text { and EQ-5D VAS change } \\
\text { from baseline }[1.03 \text { ( } 95 \% \text { CI } 1.00 \\
\text { to } 1.06)]\end{array}$ \\
\hline $\begin{array}{l}\text { Satisfaction with how } \\
\text { demanding treatment is }\end{array}$ & $180 / 267(67 \%)$ & $220 / 286(77 \%)$ & $\begin{array}{c}1.61(1.11 \text { to } 2.34) ; \\
P=0.01\end{array}$ & $\begin{array}{c}1.43(0.91 \text { to } 2.24) \\
P=0.12\end{array}$ & $\begin{array}{l}\text { HIV symptoms scale change from } \\
\text { baseline [0.98 ( } 95 \% \text { CI: } 0.95 \text { to } \\
1.00) \text { ], age [1.03 (95\% CI: } 1.00 \text { to } \\
1.05) \text {, and sex [2.72 (95\% CI: } 1.03 \\
\text { to } 7.18) \text { ] }\end{array}$ \\
\hline Flexibility of treatment & $176 / 271(65 \%)$ & $217 / 285(76 \%)$ & $\begin{array}{c}1.72(1.19 \text { to } 2.49) \\
P=0.004\end{array}$ & $\begin{array}{c}1.54(0.99 \text { to } 2.38) \\
P=0.06\end{array}$ & $\begin{array}{l}\text { CES-D score change from baseline } \\
\text { [0.96 ( } 95 \% \text { CI: } 0.93 \text { to } 0.98)] \text {, age } \\
\text { [1.02 (95\% CI: } 1.00 \text { to } 1.05) \text { ], sex } \\
\text { [3.44 (95\% CI: } 1.30 \text { to } 9.10)]\end{array}$ \\
\hline $\begin{array}{l}\text { Satisfaction with } \\
\text { understanding of HIV }\end{array}$ & $232 / 266(87 \%)$ & $252 / 287(88 \%)$ & $\begin{array}{c}1.05(0.64 \text { to } 1.74) \\
P=0.84\end{array}$ & $\begin{array}{c}1.08(0.60 \text { to } 1.94) \\
P=0.78\end{array}$ & \\
\hline $\begin{array}{l}\text { Extent with which treatment } \\
\text { fits into lifestyle }\end{array}$ & $203 / 264(77 \%)$ & $250 / 287(87 \%)$ & $\begin{array}{c}2.03(1.29 \text { to } 3.17) \\
P=0.002\end{array}$ & $\begin{array}{c}2.12(1.22 \text { to } 3.66) \\
P=0.007\end{array}$ & \\
\hline Recommendation to a friend & $230 / 266(86 \%)$ & $267 / 288(93 \%)$ & $\begin{array}{c}1.99(1.13,3.51) \\
P=0.02\end{array}$ & $\begin{array}{c}2.21(1.09 \text { to } 4.51) \\
P=0.03\end{array}$ & \\
\hline Continuation of treatment & $230 / 266(86 \%)$ & $252 / 286(88 \%)$ & $\begin{array}{c}1.16(0.70 \text { to } 1.92) \\
P=0.56\end{array}$ & $\begin{array}{c}1.43(0.77 \text { to } 2.63) \\
P=0.26\end{array}$ & $\begin{array}{l}\text { EQ-5D VAS scale change from } \\
\text { baseline [0.97 ( } 95 \% \text { CI: } 0.95 \text { to } \\
0.99) \text { ] and CES-D change from } \\
\text { baseline [0.95 ( } 95 \% \text { CI: } 0.91 \text { to } \\
0.99) \text { ]. }\end{array}$ \\
\hline
\end{tabular}

*Adjusted for change from baseline in CES-D, HIV symptoms scale, and EQ-5D VAS and baseline factors: age (yr) and sex (transgender male to female = female, ORs estimated for female vs male).

a friend were significantly higher in participants taking the 3pill once-daily DRV/r + TDF/FTC regimen compared with 4pill $\mathrm{DRV} / \mathrm{r}+\mathrm{RAL}$ regimen requiring twice-daily intake, possibly reflecting a preference for a simplified regimens with less daily intake. A meta-analysis of randomized clinical trials has shown that lower pill burden was associated with both better adherence and virological suppression. ${ }^{23}$ However, once-daily regimens were associated with slightly better adherence, but not virological suppression, as compared with twice-daily regimens. ${ }^{23}$ Absence of differences in satisfaction with regards to side effects and HIV disease control and knowledge between randomized groups is in line with findings of the study showing non-inferiority of virological efficacy and no differences in safety over follow-up. ${ }^{8}$ In fact, even if participants were less satisfied with twice-daily regimens and less prone to recommend such a regimen, this did not translate in poorer outcome at W96. Indeed, the finding of a 2-point difference in treatment satisfaction score, although statistically significant, did not seem to have much clinical relevance because it did not seem to be associated with any adverse patient-reported or clinical outcomes. Furthermore, participants on twice-daily DRV/r + RAL regimen were equally satisfied to continue on their current regimen than those on once-daily DRV/r + TDF/FTC, probably because of perceived benefit in terms of virologic suppression and immunologic recovery.

The study limitations primarily arise from the nature of any clinical trial study that has strict enrollment criteria and close follow-up. In this context, the findings from an efficacy trial may potentially have limited generalizability to the entire HIV population. However, the design of our study was pragmatic with a wide range of enrollment criteria and similar follow-up to routine care. In addition, some parameters that could potentially be associated with PROs were not collected during the study. These include level of education, marital status, income, and type of work. Finally, some of the PRO instruments were not systematically validated in all languages used in this study. Nevertheless, all these instruments have been systematically translated with some face-to-face and content validation. We also acknowledge that EQ-5D might 
lack sensitivity and may not capture subtle differences in participants' quality of life.

In summary, this randomized-controlled trial of twice-daily DRV/r + RAL vs once-daily DRV/r + TDF/ FTC demonstrated significant and persistent improvement of PRO scores during treatment. PROs improve rapidly after treatment initiation, with no difference between arms, reflecting probable improvement in immunovirologic status and/or suggestive perception of disease control while on therapy. However, treatment satisfaction was significantly lower with the twice-daily regimen for convenience and fitting into the participants' lifestyles, without affecting W96 outcome. These findings provide a comprehensive approach when treating and selecting initial ART in HIVinfected participants.

\section{ACKNOWLEDGMENTS}

The authors thank the NEAT001/ANRS143 study participants and their partners, families, and caregivers for participation in the study. The authors also thank the staff from all the centers participating in the trial.

\section{REFERENCES}

1. Palella FJ Jr, Deloria-Knoll M, Chmiel JS, et al. Survival benefit of initiating antiretroviral therapy in HIV-infected persons in different CD4 + cell strata. Ann Intern Med. 2003;138:620-626.

2. Group ISS, Lundgren JD, Babiker AG, et al. Initiation of antiretroviral therapy in early asymptomatic HIV infection. $N$ Engl J Med. 2015;373: 795-807.

3. Panel on Antiretroviral Guidelines for Adults and Adolescents. Guidelines for the Use of Antiretroviral Agents in Adults and Adolescents Living with HIV. Department of Health and Human Services. Available at: http://www.aidsinfo.nih.gov/ContentFiles/AdultandAdolescentGL. pdf. Accessed December 14, 2017.

4. Marcellin F, Preau M, Ravaux I, et al. Self-reported fatigue and depressive symptoms as main indicators of the quality of life (QOL) of patients living with HIV and Hepatitis C: implications for clinical management and future research. HIV Clin Trials. 2007;8:320-327.

5. Campo RE, Cohen C, Grimm K, et al. Switch from protease inhibitor- to efavirenz-based antiretroviral therapy improves quality of life, treatment satisfaction and adherence with low rates of virological failure in virologically suppressed patients. Int J STD AIDS. 2010;21:166-171.

6. Marcellin F, Carrieri MP, Spire B. Choice of therapeutic strategies in the context of HIV infection: key role of patient-reported outcomes. Expert Rev Anti Infect Ther. 2012;10:403-406.

7. Kozak MS, Mugavero MJ, Ye J, et al. Patient reported outcomes in routine care: advancing data capture for HIV cohort research. Clin Infect Dis. 2012;54:141-147.

8. Raffi F, Babiker AG, Richert L, et al. Ritonavir-boosted darunavir combined with raltegravir or tenofovir-emtricitabine in antiretroviralnaive adults infected with HIV-1: 96 week results from the NEAT001/ ANRS143 randomised non-inferiority trial. Lancet. 2014;384:19421951.

9. Rabin R, de Charro F. EQ-5D: a measure of health status from the EuroQol Group. Ann Med. 2001;33:337-343.

10. Bucciardini R, Pugliese K, Francisci D, et al. Validation of a selfreported HIV symptoms list: the ISS-HIV symptoms scale. AIDS Res Ther. 2016;13:18.

11. Andresen EM, Malmgren JA, Carter WB, et al. Screening for depression in well older adults: evaluation of a short form of the CES-D (Center for Epidemiologic Studies Depression Scale). Am J Prev Med. 1994;10:7784.

12. Woodcock A, Bradley C. Validation of the revised 10-item HIV Treatment Satisfaction Questionnaire status version and new change version. Value Health. 2006;9:320-333.
13. Fairclough DL, Thijs H, Huang IC, et al. Handling missing quality of life data in HIV clinical trials: what is practical? Qual Life Res. 2008;17:6173.

14. White IR, Horton NJ, Carpenter J, et al. Strategy for intention to treat analysis in randomised trials with missing outcome data. BMJ. 2011;342: d40.

15. Edelman EJ, Gordon K, Rodriguez-Barradas MC, et al. Patient-reported symptoms on the antiretroviral regimen efavirenz/emtricitabine/tenofovir. AIDS Patient Care STDS. 2012;26:312-319.

16. Nglazi MD, West SJ, Dave JA, et al. Quality of life in individuals living with HIV/AIDS attending a public sector antiretroviral service in Cape Town, South Africa. BMC Public Health. 2014;14:676.

17. Winston A, Stohr W, Antinori A, et al. Changes in cognitive function over 96 weeks in naive patients randomized to darunavir-ritonavir plus either raltegravir or tenofovir-emtricitabine: a substudy of the NEAT001/ ANRS143 trial. J Acquir Immune Defic Syndr. 2017;74:185-192.

18. Hong S, Banks WA. Role of the immune system in HIV-associated neuroinflammation and neurocognitive implications. Brain Behav Immun. 2015;45:1-12.

19. Spire B, Nait-Ighil L, Pugliese P, et al. Quality of life improvement in HIV-1 patients treated with raltegravir in a real-life observational study: RACING. HIV Clin Trials. 2017;18:1-16

20. Younossi ZM, Stepanova M, Charlton M, et al. Patient-reported outcomes with sofosbuvir and velpatasvir with or without ribavirin for hepatitis $\mathrm{C}$ virus-related decompensated cirrhosis: an exploratory analysis from the randomised, open-label ASTRAL-4 phase 3 trial. Lancet Gastroenterol Hepatol. 2016;1:122-132.

21. Jong E, Oudhoff LA, Epskamp C, et al. Predictors and treatment strategies of HIV-related fatigue in the combined antiretroviral therapy era. AIDS. 2010;24:1387-1405.

22. Nanni MG, Caruso R, Mitchell AJ, et al. Depression in HIV infected patients: a review. Curr Psychiatry Rep. 2015;17:530.

23. Nachega JB, Parienti JJ, Uthman OA, et al. Lower pill burden and once-daily antiretroviral treatment regimens for HIV infection: a metaanalysis of randomized controlled trials. Clin Infect Dis. 2014;58 $1297-1307$

\section{APPENDIX 1. NEAT 001/ANRS 143 Study Group}

\section{Trial Development Team (TDT)}

Belgium: N.D. (Brussels); France: Geneviève Chêne, L.R. (Bordeaux), Clotilde Allavena, F.R. (Nantes), and Brigitte Autran (Paris); Italy: Andrea Antinori, Raffaella Bucciardini, and S.V. (Rome); Poland: A.H. (Warsaw); Spain: Jose Arribas (Madrid); and United Kingdom: Abdel G. Babiker, Marta Boffito, Deenan Pillay, and A.P. (London).

\section{Trial Steering Committee (TSC)}

Belgium: Xavier Franquet and Siegfried Schwarze (Brussels); Denmark: Jesper Grarup (Copenhagen); France: Geneviève Chêne, Aurélie Fischer, L.R., Cédrick Wallet (Bordeaux), F.R. (Nantes), Alpha Diallo, J.M.M., and Juliette Saillard (Paris); Germany: Christiane Moecklinghoff (Janssen Pharmaceuticals; Neuss) and Hans-Jürgen Stellbrink (Hamburg); Italy: S.V. (Rome); the Netherlands: Remko Van Leeuwen (Amsterdam); Spain: Jose Gatell (Barcelona); Sweden: Eric Sandstrom (Stockholm); Switzerland: Markus Flepp (Zurich); United Kingdom: Abdel G. Babiker, Fiona Ewings, E.C.G., Fleur Hudson, and A.P. (London); and United States: Gillian Pearce, Romina Quercia, Felipe Rogatto (Gilead Sciences; Foster City, CA), Randi Leavitt, and Bach-Yen Nguyen (Merck Laboratories; Whitehouse Station, NJ).

\section{Trial Management Team (TMT)}

France: Clotilde Allavena and F.R. (Nantes); Italy: S.V. (Rome); and United Kingdom: A.P. (London).

\section{CMG-EC, INSERM U897 Coordinating Unit, Bordeaux, France}

Geneviève Chêne, Head of coordinating CTU, Member; Other Members: Fabien Arnault, Aurélie Fischer, Virginie Paniego, L.R., Christine 
Schwimmer, M.T., Guillaume Touzeau, and Cédrick Wallet; Observers: Céline Boucherie, Delphine Jean, Felasoa Paraina, Elodie Rouch, Malika Soussi, and Audrey Taieb.

\section{MRC Clinical Trials Coordinating Unit, London, United Kingdom}

Trial Statisticians: Abdel G. Babiker, Fiona Ewings, and E.C.G.; Other members: Wendy Dodds and Fleur Hudson; Observers: Adam Cursley, Anne Hoppe, Ischa Kummeling, Filippo Pacciarini, Nick Paton, Charlotte Russell, Kay Taylor, and Denise Ward.

\section{Centre for Health and Infectious Disease Research (CHIP), Copenhagen, Denmark}

Members: Daniela Gey, Jesper Grarup, Per O. Jansson, Karoline Jensen, Mary Pearson, Birgit Riis Nielsen; Observers: Bitten Aagaard, Marius Eid, Birgitte Gram Jensen, Marie-Louise Jakobsen, Zillah Maria Joensen, Ellen Moseholm Larsen, Christiane Pahl, Birgit Riis Nielsen, and Søren Stentoft Reilev.

\section{Amsterdam Medical Center Coordinating Unit, Amsterdam, the Netherlands}

Members: Desiree Lathouwers, Corry Manting, and Remko Van Leeuwen; Observers: Ilse Christ.

\section{INSERM-ANRS, Paris, France}

Members: Alpha Diallo, Bienvenu Yves Mendy, Annie Metro, Juliette Saillard, and Sandrine Couffin-Cadiergues.

\section{ISS, Rome, Italy}

Member: Lucia Palmisiano; Observer: Anne-Laure Knellwolf.

\section{Local Clinical Trials Units (CTUs)}

GESIDA, Madrid, Spain: Esther Aznar, Cristina Barea, Manuel Cotarelo, Herminia Esteban, Iciar Girbau, Beatriz Moyano, Miriam Ramirez, Carmen Saiz, Isabel Sanchez, and Maria Yllescas; ISS, Rome, Italy: Andrea Binelli, Valentina Colasanti, Maurizio Massella, and Lucia Palmisiano; University of Athens Medical School, Greece: Olga Anagnostou, Vicky Gioukari, and Giota Touloumi.

\section{Study Investigators}

Austria: Brigitte Schmied (National Coordinating Investigator), Armin Rieger, and Norbert Vetter; Belgium: Stephane De Wit (National Coordinating Investigator), Eric Florence, and Linos Vandekerckhove; Denmark: Jan Gerstoft (National Coordinating Investigator) and Lars Mathiesen; France: Christine Katlama (National Coordinating Investigator), André Cabié, Antoine Cheret, Michel Dupon, Jade Ghosn, Pierre-Marie Girard, Cécile Goujard, Yves Lévy, J.-M.M., Philippe Morlat, Didier Neau, Martine Obadia, and Philippe.

Perré, Lionel Piroth, Jacques Reynes, Pierre Tattevin, F.R., Jean Marie Ragnaud, Laurence Weiss, Yazdan Yazdanpanah, Patrick Yéni, and David Zucman; Germany: Georg Behrens (National Coordinating Investigator), Stefan Esser, Gerd Fätkenheuer, Christian Hoffmann, Heiko Jessen, Jürgen Rockstroh, Reinhold Schmidt, Christoph Stephan, and Stefan Unger; Greece: Angelos Hatzakis (National Coordinating Investigator), George L. Daikos, Antonios Papadopoulos, and Athamasios Skoutelis; Hungary: Denes Banhegyi (National Coordinating Investigator); Ireland: Paddy Mallon (National Coordinating Investigator) and Fiona Mulcahy; Italy: Andrea Antinori (National Coordinating Investigator), Massimo Andreoni, Stefano Bonora, Francesco Castelli, Antonella D'Arminio Monforte, Giovanni Di Perri, Massimo Galli, Adriano Lazzarin, Francesco Mazzotta, Torti Carlo, and Vincenzo Vullo; the Netherlands: Jan Prins (National Coordinating Investigator), Clemens Richter, Dominique Verhagen, and Arne Van Eeden; Poland: A.H. (National Coordinating Investigator); Portugal: Manuela Doroana (National Coordinating Investigator), Francisco Antunes, Fernando Maltez, and Rui Sarmento-Castro; Spain: Juan Gonzalez Garcia (National Coordinating Investigator), Jose Lopez Aldeguer, Bonaventura Clotet, Pere Domingo, Jose M. Gatell, Hernando Knobel, Manuel Marquez, Martin Pilar Miralles, Joaquin Portilla, Vicente Soriano, and Maria-Jesus Tellez; Sweden: Anders Thalme (National Coordinating Investigator), Anders Blaxhult, and Magnus Gisslen; United Kingdom: Alan Winston (National Coordinating Investigator), Julie Fox, Mark Gompels, Elbushra Herieka, Margaret Johnson, Clifford Leen, A.P., Alastair Teague, and Ian Williams.

\section{Quality-of-Life Working Group}

Raffaella Bucciardini (coordinator), N.D., Vincenzo Fragola, E.C.G. (statistician), Marco Lauriola, Rita Murri, Pythia Nieuwkerk, Bruno Spire, Alain Volny-Anne, and Brian West. 